\title{
Custos Logísticos: o Caso de uma Indústria Beneficiadora de
}

Arroz

\begin{abstract}
Andréia Cittadin
Doutorado em andamento em Contabilidade pela Universidade Federal de Santa

Catarina - UFSC

Professora e coordenadora de estágio do curso de Ciências Contábeis na Universidade do Extremo Sul Catarinense - UNESC Av. Universitária, 1105. Universitário. Criciúma/SC. CEP: 88.806-000, Brasil

E-mail: aci@unesc.net

Kaline Ribeiro Mantovani Bacharelado em Ciências Contábeis pela Universidade do Extremo Sul Catarinense UNESC.

Assistente de Faturamento na empresa Realengo Alimentos Rua Luiz Cirimbelli, 1047. Bairro Imigrantes. Turvo/SC. CEP: 88.930-000 E-mail:k_line.mantovane@hotmail.com
\end{abstract}

Michele Domingos Schneider Doutorado em andamento em Desenvolvimento SocioEconômico pela Universidade do Extremo Sul Catarinense - UNESC Professora e Coordenadora dos Cursos de Tecnologia em Gestão Comercial na Universidade do Extremo Sul Catarinense - UNESC Av. Universitária, 1105. Universitário. Criciúma/SC. CEP: 88.806-000, Brasil E-mail: michele.schneider@unesc.net

Leopoldo Pedro Guimarães Filho Doutorado em Ciências Ambientais pela Universidade do Extremo Sul Catarinense UNESC Professor e Coordenador do curso de Engenharia de Produção na Universidade do Extremo Sul Catarinense - UNESC Av. Universitária, 1105. Universitário. Criciúma/SC. CEP: 88.806-000, Brasil E-mail: Ipg@unesc.net

\section{RESUMO}

A logística se configura pelo gerenciamento das atividades e fluxo de informações relativas à movimentação de materiais ao longo da cadeia de suprimentos, com vista à redução de custos e melhoria dos níveis de serviço. Este estudo tem como objetivo identificar os custos logísticos de uma indústria beneficiadora de arroz do sul catarinense. A metodologia compreende a pesquisa descritiva, com abordagem qualitativa e estudo de caso único. Os dados coletados referem-se ao ano de 2018, obtidos por meio de análise documental e entrevistas. Foram descritas as atividades que compõe a cadeia de suprimentos da entidade, que abrange operações desde o recebimento e armazenagem da matéria-prima, beneficiamento do arroz, transferências 
Custos Logísticos: o Caso de uma Indústria Beneficiadora de Arroz

Andréia Cittadin, Kaline Ribeiro Mantovani, Michele Domingos Schneider, Leopoldo Pedro Guimarães

Filho

para os centros de distribuição e entrega do produto final aos clientes. Os resultados permitiram identificar que o processo logístico de distribuição é o que gera maiores gastos para a organização ( $21,46 \%$ sobre o faturamento); os custos de transportes possuem maior representatividade em relação aos custos logísticos totais $(68,76 \%)$; e os custos logísticos totais da empresa em estudo representaram $26,25 \%$ sobre seu faturamento. Conclui-se que o gerenciamento logístico é fundamental para a redução de custos, melhoria dos processos e serviços aos clientes e geração de vantagens competitivas.

Palavras-chave: Gestão de Custos. Processos Logísticos. Cerealista de arroz.

Logistic Costs: the Case of a Rice Processing Industry

\section{ABSTRACT}

Logistics is configured by the management of activities and information flow related to the movement of materials along the supply chain, for reducing costs and improving the service provided. This study aims to identify the logistical costs of a rice processing industry in southern Santa Catarina. The methodology comprises descriptive research, with a qualitative approach and a single case study. The data collected refer to 2018, obtained through document analysis and interviews. The activities that make up the entity's supply chain were described, covering operations from the receipt and storage of raw material, rice processing, transfers to distribution centers and delivery of the final product to customers. The results made it possible to identify that the logistical distribution process may generates the highest expenses for the organization $(21.46 \%$ on turnover); transport costs are more representative than total logistical costs $(68.76 \%)$, and the total logistical costs of the company under study represented $26.25 \%$ of its turnover. We conclude that logistical management is fundamental for reducing costs, improving processes and services to customers and generating competitive advantages.

Keywords: Cost Management. Logistic Processes. Rice cereal.

\section{Costos logísticos: el caso de una industria procesadora de arroz}

\section{RESUMEN}

La logística se configura mediante la gestión de las actividades y el flujo de información relacionada con el movimiento de materiales a lo largo de la cadena de suministro, con el fin de reducir costos y mejorar los niveles de servicio. Este estudio tiene como objetivo identificar los costos logísticos de una industria procesadora de arroz en el sur de Santa Catarina. La metodología comprende una investigación descriptiva, con un enfoque cualitativo y un estudio de caso único. Los datos recopilados se refieren al año 
2018, obtenidos mediante análisis documental y entrevistas. Se describieron las actividades que componen la cadena de suministro de la entidad, abarcando operaciones desde la recepción y almacenamiento de materia prima, procesamiento de arroz, traslados a centros de distribución y entrega del producto final a los clientes. Los resultados permitieron identificar que el proceso de distribución logística es el que genera mayores gastos para la organización (21,46\% sobre facturación); los costos de transporte son más representativos que los costos logísticos totales $(68,76 \%)$; y los costos logísticos totales de la empresa en estudio representaron el $26,25 \%$ de su facturación. Concluye que la gestión logística es fundamental para reducir costos, mejorar procesos y servicios a los clientes y generar ventajas competitivas.

Palabras clave: Gestión de costos. Procesos logísticos. Cereal de arroz.

\section{INTRODUÇÃO}

As transformações econômicas, políticas, sociais e tecnológicas presentes no atual cenário mercadológico exigem das empresas gestão eficaz, de modo a identificar e desenvolver estratégias no intuito de promover melhorias em seus processos (Soares \& Jacometti, 2016). A contabilidade de custos é a área responsável por identificar os custos envolvidos nos processos, produtos e serviços, com intuito de analisá-los e buscar alternativas para reduzi-los. A partir disso, é possível diminuir o preço cobrado dos consumidores e, assim, obter possibilidade de gerar vantagem competitiva em relação aos concorrentes, focando na estratégia de baixo custo (Ferreira, 2007).

Para obter vantagem competitiva é essencial conhecer a cadeia de suprimentos da empresa, a fim de entender como funcionam seus processos, do ponto de origem da matéria-prima até a entrega do produto aos consumidores finais (Cunha \& Cruz, 2017). Nesse sentido, identificar os custos logísticas ao longo da cadeia de suprimentos e fundamental para reduzir os gastos e disponibilizar produtos com preços mais acessíveis. Ademais, para manter o nível de serviço desejado ao cliente é fundamental diminuir os custos logísticos (Hansen, Hovi, \& Veisten, 2014).

Em relação à economia brasileira vale citar o agronegócio, uma vez que contribui significativamente para o equilíbrio da balança comercial, além de promover o desenvolvimento econômico pela oferta de produtos, geração de divisas (Santos, 
Avelar, Shikida, \& Carvalho, 2016) emprego e renda (Soares \& Jacometti, 2016). Porém, o setor agrícola enfrenta desafios relacionados às questões do clima, da economia e das políticas, que acabam refletindo na produtividade e no preço do produto (Soares \& Jacometti, 2016). Logo, é necessário manter elevado nível de competitividade em relação a custos, preços e qualidade, esses condizentes com as exigências dos consumidores (Gasques, Bastos, Bacchi, \& Valdes, 2010).

A cadeia de valor do arroz é considerada uma das mais importantes, uma vez que esse produto é consumido diariamente por grande parte da população (Souza, Arbage, \& Corazza, 2006). O Brasil é o maior produtor do grão fora da Ásia, de acordo com o Instituto Brasileiro de Geografia e Estatística - IBGE (2017), a região Sul é a principal produtora de arroz do país. O estado de Santa Catarina possui 25.000 rizicultores, distribuídos em cerca de 200 cidades (Empresa de Pesquisa Agropecuária e Extensão Rural de Santa Catarina [Epagri] 2018). Existem 28 agroindústrias associadas ao Sindicato da Indústria do Arroz no Estado de Santa Catarina - Sindarroz, que apresentam capacidade de beneficiamento de 1,4 milhões de toneladas de arroz em casca por ano. Desse montante, um milhão refere-se ao Estado e o restante, 400 milhões de toneladas, são adquiridos do Rio Grande do Sul (Sindarroz, 2018).

Inserida neste contexto, tem-se uma agroindústria localizada no sul do Estado, cuja vendas para o norte e nordeste do país correspondem, em média, 47,32\% do faturamento total. Com isso, percebe-se a necessidade de identificar e analisar os custos logísticos envolvidos em seus processos logísticos. Diante do exposto, tem-se a seguinte questão de pesquisa: Quais os custos logísticos que integram a cadeia de suprimentos de uma indústria beneficiadora de arroz? O objetivo geral deste estudo consiste em identificar os custos logísticos de uma indústria beneficiadora de arroz. A partir do objetivo geral, tem-se os seguintes objetivos específicos: a) descrever os processos logísticos que compõem a cadeia de suprimentos da agroindústria; b) identificar os custos envolvidos nos processos logísticos de abastecimento, planta e distribuição; e, c) mensurar os custos logísticos nesses processos. 
A contribuição teórica deste estudo está na aplicabilidade de um modelo de evidenciação de custos logísticos em um contexto específico para empresas que beneficiam e comercializam arroz. Franco e Gasparetto (2020) observam que para ampliar a compreensão sobre a temática é preciso realizar mais pesquisas sobre o assunto considerando os contextos locais.

Para Hansen et al., (2014), a falta de informação sobre os custos logísticos totais, bem como de cada atividade logística, é um entrave em relação à eficiência de custos da cadeia de abastecimento. Dessa forma, a pesquisa poderá contribuir com a empresa em estudo, pois buscou evidenciar os custos logísticos nos processos de abastecimento, planta e distribuição. Assim, apresenta oportunidade de redução de custos, em virtude de identificar aqueles que representam maior representatividade na estrutura dos custos logísticos totais e melhoria nos processos. Segundo Engblom, Solakivi, Töyli e Ojala (2012) os custos logísticos equivalem uma parcela significativa em relação aos custos totais e, muitas vezes, ultrapassam $10 \%$ do faturamento das empresas, fato que justifica seu gerenciamento.

No âmbito social, a pesquisa poderá contribuir servindo de base para estudos posteriores, uma vez que evidenciando os custos logísticos envolvidos nos processos de uma indústria beneficiadora de arroz, outras indústrias desse segmento, principalmente da região, poderão analisar os custos presentes em seus processos. Ademais, acredita-se que com a gestão de custos logísticos será possível gerar melhores resultados financeiros e econômicos das beneficiadoras de arroz, oportunizando a comercialização de seus produtos com preços mais acessíveis e qualidade superior.

\section{FUNDAMENTAÇÃO TEÓRICA}

\subsection{Histórico e conceito de logística}

A primeira definição do termo logística deu-se pelo general do exército francês Barão Antoine Henri de Jomini, conceituando-a como uma forma prática de movimentar 
exércitos Durante a Segunda Guerra Mundial (Rodrigues, 2004). O conceito de logística adquiriu maior amplitude em razão do aumento das operações militares, o que fez com que a demanda de suprimentos crescesse de forma significativa, passando a requerer melhor eficiência de abastecimento. A vinculação da logística ao atendimento das necessidades militares, oportunizou as Forças Armadas à percepção de que a logística compreendia o conjunto de atividades capaz de provisionar e administrar materiais, pessoas e instalações, bem como obter serviços de apoio (Ballou, 2007).

Esses conceitos foram aplicados na gestão empresarial, conforme afirmam Bowersox e Closs (2004), pois a dependência de fornecedores externos e das atividades de compras, controle de estoques e transportes são mais evidentes nas indústrias, já que ao longo do processo fabril as matérias-primas necessitam ser armazenadas, transformadas e, finalmente, distribuídas aos consumidores.

Assim, após a Segunda Guerra Mundial, na década de 1960 foi o período em que as indústrias estavam se reconstruindo, logo representou o marco para o desenvolvimento teórico e prático da logística na gestão empresarial (Rodrigues, 2004). No início dos anos 1970, os custos de distribuição cresceram de forma significativa por conta da crise do petróleo que elevou os preços dos combustíveis, tal fato fez com que as empresas aumentassem sua preocupação com o gerenciamento de custos (Rodrigues, 2004). A partir da década de 1980, com o uso da tecnologia e dos sistemas informatizados, os ciclos operacionais tornaram-se mais curtos, requerendo um processo decisório mais eficiente, dessa forma, o controle e análise do processo logístico permitiu a criação de indicadores de custos, o que trouxe maior flexibilidade perante as operações, possibilitando oportunidades mais lucrativas (Ballou, 2007; Faria \& Costa, 2005; Rodrigues, 2004).

De acordo com Novaes (2007), no início a logística era compreendida como um mero centro de custo dentro das organizações. Com o passar do tempo, essa área passou a não exercer apenas a função de armazenar, disponibilizar bens para o processo de transformação e transportar mercadorias, passou a agregar valor aos processos e aumentar o desempenho operacional da empresa, conquistando espaço 
significativo na gestão empresarial (Faria \& Costa, 2005). Hansen et al. (2014) também observam que tradicionalmente a logística limitava-se as atividades pertinentes à distribuição e armazenamento de produtos acabados. Porém, esse entendimento se ampliou para uma visão mais abrangente e integrada, passando a contemplar de modo mais estratégico os processos de aquisição, movimentação e armazenamento de materiais e distribuição de produtos acabados, considerando custos e desempenho.

A logística moderna é concebida como processo de planejamento, direção, execução e controle, de um fluxo de bens, produtos e serviços, os fluxos de materiais e fluxos financeiros, do ponto de origem ao ponto de consumo, de uma forma eficiente e eficaz economicamente, visando a satisfação do cliente (Ballou, 2007).

Portando, a logística é fundamental na definição de estratégias competitivas, pois oportuniza a reestruturação dos processos operacionais e melhoria no desempenho da organização, a fim atender as necessidades dos clientes, os quais buscam qualidade do produto e rapidez no atendimento e prestação de serviços, de modo a confrontar essas variáveis com o preço (Rodrigues, 2004). Desse modo, a análise e controle das atividades logísticas são essenciais para o desenvolvimento da organização e melhoria dos processos perante sua cadeia de valor (Silva \& Leite, 2012).

Para atender o nível de serviço desejado, que seria alcançar resultados de acordo com a expectativa e o plano de qualidade esperado pela empresa, a logística precisa envolver e integrar as atividades de transporte, estoque, armazenamento, manuseio de materiais e embalagem e fluxo de informações (Bowersox \& Closs, 2004). Essas atividades devem estar relacionadas em si, já que a logística integrada garante a disponibilidade e agilidade de serviços, de modo que determinado setor da empresa fornece informação a outro, desse modo possibilita agilizar processos e garantir a satisfação dos clientes (Bowersox, Closs, \& Cooper, 2007).

\subsection{Cadeia Logística}

Bowersox et al. (2007) afirmam que é por meio dos processos logísticos que os materiais fluem para o sistema produtivo e os produtos acabados chegam até os 
consumidores finais. Para tanto, a logística divide-se em três processos, sendo esses: logística de abastecimento, logística de planta e logística de distribuição.

A logística de abastecimento é responsável por suprir o sistema produtivo com matéria-prima e demais insumos necessários para desenvolver as atividades da empresa (Bowersox et al., 2007). De acordo com Bowersox et al. (2007), um dos principais objetivos da aquisição de materiais é o apoio à manufatura ou atividades de revenda, isso mediante às compras efetuadas no tempo correto, com menor custo.

A logística de planta envolve as atividades responsáveis pelo fluxo de materiais para o processo produtivo. Segundo Faria, Robles e Bio (2004), esse processo engloba os procedimentos desde o recebimento de matérias-primas nas linhas produtivas, ao suporte logístico necessário à fabricação e a entrega dos produtos finais à expedição.

Os principais custos que podem estar relacionados a logística de planta estão inseridos nos subprocessos de manutenção de inventário de produtos em processo; manuseio e movimentação dos produtos em processo, tais como mão de obra e depreciações. Para Faria e Costa (2005), a logística de planta inclui, também, os custos decorrentes de lotes e com planejamento, programação e controle de produção (PCP), que são gastos ligados a sincronização das entradas de materiais para que as necessidades de saída de produtos sejam atendidas, além dos gastos com os sistemas utilizados referente a tecnologia da informação.

A logística de distribuição é responsável pela entrega dos produtos aos clientes. Esse processo ocorre da seguinte maneira: inicialmente a empresa recebe a solicitação do pedido e verifica a disponibilidade do produto; caso o produto se encontre disponível, o pedido é efetivado e acontece a separação, inspeção, embalagem, faturamento, emissão da nota fiscal e do conhecimento de frete, consolidação da carga e, por fim, a expedição (Faria \& Costa, 2005).

Os custos logísticos incorridos no processo de distribuição estão representados pelos subprocessos de embalagem; armazenagem e movimentação; estocagem, pois a presença de estoques em uma organização eleva o nível do serviço prestado ao cliente, visto que esses disponibilizam produtos e serviços com menor tempo de espera, 
com isso, mantendo e aumentando as vendas; tecnologia da informação em decorrência das funções relacionadas ao recebimento, processamento e rastreamento dos pedidos por meio de softwares; tributários referentes ao transporte, taxas e tarifas alfandegárias na exportação; e transportes, o qual pode ser realizado pelos modais rodoviário, ferroviário, aquaviário, aeroviário, e dutoviário (Ballou, 2001).

Destaca-se que os custos de transportes são considerados os mais relevantes entre os custos logísticos, pois compreendem o deslocamento externo do fornecedor à empresa, bem como da empresa ao cliente (Faria \& Costa, 2005). Assim sendo, a definição do modal de transporte a ser utilizado contribui para a redução dos custos logísticos, uma vez que que pode assegurar economia significativa para a empresa, bem como elevar o nível de desempenho no que diz respeito aos serviços prestados (Novaes, 2007).

De modo geral, os gastos existentes após a fabricação podem ser considerados como custos de distribuição (Faria \& Costa, 2005). A logística de distribuição tem o objetivo de disponibilizar a quantidade de mercadorias certa, no momento certo e no lugar certo, visando otimização de processos e redução de custos (Bowersox et al., 2007).

Segundo Souza, Zwirtes, Rodniski e Borghetti (2013) ao passo que a logística passou a ser compreendida como uma forma de desenvolver vantagens competitivas, os custos logísticos ganharam relevância na gestão estratégica das organizações.

\subsection{Custos Logísticos}

De acordo com o Institute of Management Accountants - IMA (como citado em Faria et al., 2004) os custos logísticos referem-se aos "custos de planejar, implementar e controlar todo o inventário de entrada (inbound), em processo e de saída (outbound), desde o ponto de origem até o ponto de consumo" (p.4).

Para Engblom et al. (2012) os custos logísticos totais compreendem os custos com transporte, armazenamento, manutenção de estoque, administração logística, embalagem e custos indiretos de logística. Faria e Costa (2005) classificam os custos 
Custos Logísticos: o Caso de uma Indústria Beneficiadora de Arroz

Andréia Cittadin, Kaline Ribeiro Mantovani, Michele Domingos Schneider, Leopoldo Pedro Guimarães

Filho

logísticos da seguinte maneira: i) armazenagem e movimentação; ii) transportes; iii) embalagens; iv) manutenção de inventário; v) tecnologia de informação; vi) tributários; vii) decorrente de lotes; e, viii) decorrente de nível de serviço, os quais podem ser denominados de subprocessos. O Quadro 1 relaciona esses subprocessos com seus respectivos custos.

\begin{tabular}{|c|c|}
\hline $\begin{array}{c}\text { Subprocessos } \\
\text { Logísticos }\end{array}$ & Definição \\
\hline $\begin{array}{l}\text { Armazenagem e } \\
\text { Movimentação }\end{array}$ & $\begin{array}{l}\text { Atividades diretamente ligadas ao espaço físico, manuseio e movimentação dos } \\
\text { materiais e produtos e acondicionamento dos estoques. Tem-se como exemplo os } \\
\text { custos de armazém geral, o qual envolve as taxas de armazenagem, seja por } \\
\text { unidade estocada ou movimentada, ou por área ocupada. Podendo ser também } \\
\text { custos de armazém próprio, o que contempla mão de obra, manutenções, } \\
\text { depreciações, água, luz, entre outros (Faria \& Costa, 2005). }\end{array}$ \\
\hline Transportes & $\begin{array}{l}\text { Influenciados por diversos fatores, de acordo com Bowersox e Closs (2004) são } \\
\text { estes: a distância entre o ponto de origem até o ponto de destino do produto; volume } \\
\text { e densidade do produto; facilidade de carga e descarga; responsabilidade referente } \\
\text { as características da carga transportada; e, fatores de mercado, como a } \\
\text { sazonalidade dos produtos, intensidade e facilidade de tráfego. Desta forma } \\
\text { compreende custos variáveis, como combustíveis, pedágios e outros, bem como } \\
\text { custos fixos para empresas que possuem frota própria de veículos. }\end{array}$ \\
\hline Embalagem & $\begin{array}{l}\text { Pode ser classificado em dois tipos: } 1 \text { ) embalagem para o consumidor, com ênfase } \\
\text { no marketing e apresentação do produto; e 2) embalagem voltada as operações } \\
\text { logísticas, sendo que representa a proteção do produto contra as possíveis avarias } \\
\text { ao longo dos processos de movimentação, estocagem e distribuição (Bowersox \& } \\
\text { Closs, 2004). Os custos variáveis de embalagens referem-se a materiais como: } \\
\text { madeira, papelão, plástico, aço, ferro e outros. Os custos fixos estão relacionados a } \\
\text { mão-de-obra envolvida na produção das referidas embalagens e custos com } \\
\text { depreciação e manutenção dos equipamentos utilizados. }\end{array}$ \\
\hline $\begin{array}{l}\text { Manutenção de } \\
\text { Inventário }\end{array}$ & $\begin{array}{l}\text { Os custos para manter os estoques devem incluir apenas os que variam com os } \\
\text { seus níveis e que podem ser agrupados em: custo de capital, custos de serviço de } \\
\text { inventário, custo de espaço de armazenagem e custos de risco de estoques (Faria \& } \\
\text { Costa, 2005). }\end{array}$ \\
\hline $\begin{array}{l}\text { Tecnologia da } \\
\text { Informação }\end{array}$ & $\begin{array}{l}\text { Para Faria e Costa (2005), os custos de tecnologia de informação incluem os gastos } \\
\text { relacionados ao processamento dos pedidos, assim como os relativos às } \\
\text { comunicações internas e externas e acompanhamentos, englobando: mão de obra, } \\
\text { depreciações, aluguéis de equipamentos, manutenções de hardwares e softwares, } \\
\text { mensalidade de internet, entre outros. }\end{array}$ \\
\hline Tributários & $\begin{array}{l}\text { Referem-se aos tributos não recuperáveis incidentes nas operações de aquisição e } \\
\text { vendas de produtos e serviços, que no Brasil são extremamente relevantes para as } \\
\text { empresas. Desta forma, este conceito engloba os impostos, taxas e contribuições de } \\
\text { melhoria a serem pagos ao Poder Público. }\end{array}$ \\
\hline
\end{tabular}




\begin{tabular}{|c|l|}
\hline $\begin{array}{c}\text { Decorrentes de } \\
\text { Lotes }\end{array}$ & $\begin{array}{l}\text { Ligados à atividade de setup, que consiste no preparo de uma máquina específica, } \\
\text { recurso, centro de trabalho ou linha, entre o término de produção de um item e o } \\
\text { início do próximo (Faria \& Costa, 2005). De acordo com Lambert (1994, como citado } \\
\text { em Faria \& Costa, 2005) os custos de lotes são constituídos pelos custos de preparo } \\
\text { de produção, quantidade perdida decorrente da troca de ferramentas ou mudanças } \\
\text { de máquinas e planejamento, manuseio e movimentação de matérias. }\end{array}$ \\
\hline $\begin{array}{c}\text { Decorrentes de } \\
\text { Nível de Serviço }\end{array}$ & $\begin{array}{l}\text { De acordo com Faria e Costa (2005), o custo decorrente de nível de serviço é } \\
\text { composto pelo custo de vendas perdidas (falta de mercadoria em estoque para } \\
\text { atender a demanda); as falhas (eventos que afetam a qualidade do produto); e } \\
\text { custos de não qualidade (perdas decorrentes de falhas). }\end{array}$ \\
\hline
\end{tabular}

\section{Quadro 1. Custos logísticos}

Fonte: Adaptado de Bowersox e Closs (2004) e Faria e Costa (2005).

As atividades logísticas estão presentes ao longo do fluxo de materiais e bens, seja dos fornecedores até a fabricação (logística de abastecimento), nos processos produtivos (logística de planta) e na entrega aos consumidores (logística de distribuição), seu gerenciamento visa minimizar os custos totais e maximizar o nível de serviço ao cliente (Faria \& Costa, 2005).

A partir dessa subdivisão, observa-se a abrangência dos elementos que compõem os custos logísticos, reforçando a importância de seu gerenciamento. Nesse sentido, os custos relativos às atividades logísticas se tornam relevantes no gerenciamento dos sistemas de produção, tendo em vista que representam uma parcela considerável na receita operacional das empresas (Freitas \& Mello Villar, 2007).

Destaca-se de acordo com Franco e Gasparetto (2020) que o entendimento e a forma de estabelecer as atividades que compõe os processos logísticos, bem como o modo como os custos logísticos são identificados e monitorados, tem relação com a percepção da gestão de cada organização sobre a logística. E, entre as metodologias para mensuração dos custos logísticos Engblom et al. (2012) evidenciaram aquela que se baseia nos dados disponibilizados pela empresa, pelos quais se faz uma estimativa de custos logísticos em percentuais em relação às vendas. 


\section{PROCEDIMENTOS METODOLÓGICOS}

A pesquisa caracteriza-se como descritiva, pois segundo Cervo, Bervian e Silva (2007) tem por objetivo exibir com exatidão a frequência em que um fato ocorre, sua natureza, características e igualdade com outros. Assim, este estudo visa identificar os custos logísticos pertencentes aos processos de abastecimento, planta e distribuição em uma indústria beneficiadora de arroz.

A análise dos dados empregada é qualitativa. Neste tipo de pesquisa, há uma relação entre o pesquisador e o objeto de estudo, o pesquisador deve participar, compreender e interpretar os dados obtidos, pois a pesquisa qualitativa consiste em colher e analisar dados descritivos para realizar uma análise mais profunda em relação ao objeto de estudo (Michel, 2015). Os dados foram coletados a partir dos demonstrativos contábeis e gerenciais da empresa pesquisada e, com isso, este estudo descreve, classifica e analisa os custos logísticos da organização.

Trata-se de um estudo de caso, pois esse procedimento investiga casos isolados, com o intuito de compreender fatos e fenômenos sociais. É aplicado em pesquisas que estudam uma unidade ou situação específica, com o objetivo de compreender seus termos e propor soluções ou respostas (Michel, 2015).

O estudo foi realizado em uma indústria beneficiadora de arroz localizada no sul do Estado de Santa Catarina, mediante análise documental em seus demonstrativos contábeis, gerenciais e relatórios extraídos do sistema Business Intelligence (B.I.) da empresa, como Balanço Patrimonial (BP), Demonstrativo de Resultado (DR) e Relatórios por Centro de Custos, todos com resultados consolidados da matriz, filial Rio Grande do Sul (RS), centros de distribuição e fazendas. Também foram realizadas entrevistas com colaboradores das áreas de logística, contabilidade e setor de Tecnologia da Informação (T.I.), a fim de identificar os custos logísticos presentes nos processos da organização. A coleta de dados ocorreu nos meses de abril a junho de 2019, com base nos relatórios do ano de 2018. 
Para os custos com armazenagem e movimentação foram observados os relatórios por centro de custo do Armazém, Produção e Logística; os custos de transportes com salários e encargos foram obtidos no setor de recursos humanos; os fretes sobre venda, cabotagem e portos foram extraídos do relatório por centro de custo da logística; a depreciação e manutenção da frota, combustíveis e seguros dos produtos foram extraídos do DR; os custos de embalagens foram identificados a partir do centro de custo da Produção; para identificação dos custos com manutenção de inventário foram utilizados os salários dos funcionários responsáveis pelo almoxarifado e os responsáveis pela compra de matéria-prima, esses obtidos no setor de recursos humanos; o custo de tecnologia de informação foi encontrado por meio de entrevista com funcionário da área, o qual definiu o tempo utilizado em tais atividades para o cálculo dos salários e encargos e a proporção do uso dos softwares, hardwares e internet nas atividades logísticas; Os custos tributários com IPVA (Imposto sobre a Propriedade de Veículos Automotores) foram obtidos por meio do DR da empresa; e, por fim, os custos decorrente de nível de serviço foram obtidos por meio de consulta no sistema gerencial em que consta as devoluções lançadas no período separadas por motivos; os salários e encargos foram obtidos no setor de recursos humanos; a depreciação foi extraída do DR; para as certificações foi realizada consulta das notas pagas ao fornecedor responsável pela classificação dos produtos e o valor dos descartes considerados como falhas de produção foi encontrado no sistema gerencial da empresa; o faturamento bruto foi obtido no DR.

A empresa em estudo é uma sociedade limitada que possui como atividade principal o beneficiamento e comercialização de arroz. Foi fundada em 1982 no município de Turvo, no sul de Santa Catarina, por um único empreendedor. Atualmente, possui quatro sócios, o fundador e três filhos responsáveis pela direção da empresa e conta com, aproximadamente, 180 funcionários, desses 36 estão alocados na área administrativa e 144 na produção. 
A empresa possui uma filial no Rio Grande do Sul, dois centros de distribuições, localizados nos Estados do Ceará e Pará e duas fazendas para plantio e armazenagem do arroz em casca, localizadas em Santa Catarina.

A estrutura organizacional é composta por 19 áreas/setores. A Direção Geral abrange três gerências: a) Gerência Administrativa, responsável pelas áreas de Recursos Humanos, Financeiro, T.I., Contabilidade, Logística, Faturamento e Compras; b) Gerência de Operações, encarregada pelo Controle de Qualidade, Produção, Expedição, Manutenção e Armazéns; e, c) Gerência Comercial, que administra os representantes responsáveis pelas vendas. Destaca-se que os gerentes dessas áreas são profissionais terceirizados que tem como apoio o setor de Contabilidade, cujo objetivo é a emissão de relatórios contábeis e gerenciais que possibilitam 0 acompanhamento do desempenho da organização. A empresa conta ainda com assessorias terceirizada nas áreas Jurídica e Marketing.

O setor de logística, subordinado a Gerência Administrativa, é composto por 04 funcionários, responsáveis pela definição de rotas, escolha do caminhão da frota própria para efetuar as entregas, contratação de frete de terceiros, cabotagem, fretes de retorno, gerenciamento dos estoques nos centros de distribuições e prestação de contas com motoristas.

A agroindústria comercializou 2.191.373 fardos de 30 quilos no período analisado, o que representou, em média, 182.615 fardos por mês. Os produtos estão classificados em 04 categorias: arroz parboilizado (56,72\%), arroz branco (39,93\%), arroz integral $(2,18 \%)$ e arroz fora do tipo $(1,17 \%)$. Os principais clientes da empresa estão localizados nos Estado do Pará, Ceará e Maranhão, com faturamento médio anual em torno de $47,32 \%, 13,18 \%$ e $11,58 \%$, respectivamente. Os clientes mais representativos são as redes Armazém Mateus, Atacadão S.A e Sendas Distribuidora, com percentuais médios de compras de aproximadamente $7,12 \%, 5,78 \%$ e 3,84\%, respectivamente. 
A empresa possui frota própria de 32 veículos, responsáveis pelo transporte dos produtos finais aos clientes e dos containers aos portos, bem como da retirada desses dos portos para transportá-los aos centros de distribuição.

\section{DESCRIÇÃO E ANÁLISE DE DADOS}

Nessa seção, inicialmente são descritos os processos logísticos que compõem a cadeia de suprimentos da agroindústria e evidenciados os custos logísticos envolvidos nestes processos. Por fim, ocorre a mensuração desses gastos.

\subsection{Cadeia de suprimentos da agroindústria}

A cadeia de suprimentos da agroindústria contempla os elos antecedentes, tais como os fornecedores de matéria-prima e demais insumos, os fluxos de produção, comercialização e distribuição dos produtos finais aos clientes. Assim, é constituída por atividades primárias, tais como: recebimento de matéria-prima e demais insumos, armazenagem e movimentação de materiais, beneficiamento e distribuição dos produtos. As atividades de apoio referem-se a: gerência geral, controle de qualidade, recursos humanos, financeiro, T.I., logística, contabilidade, faturamento, compras, marketing e setor jurídico.

A Figura 1 apresenta as atividades que compõem a cadeia de suprimentos da agroindústria: 


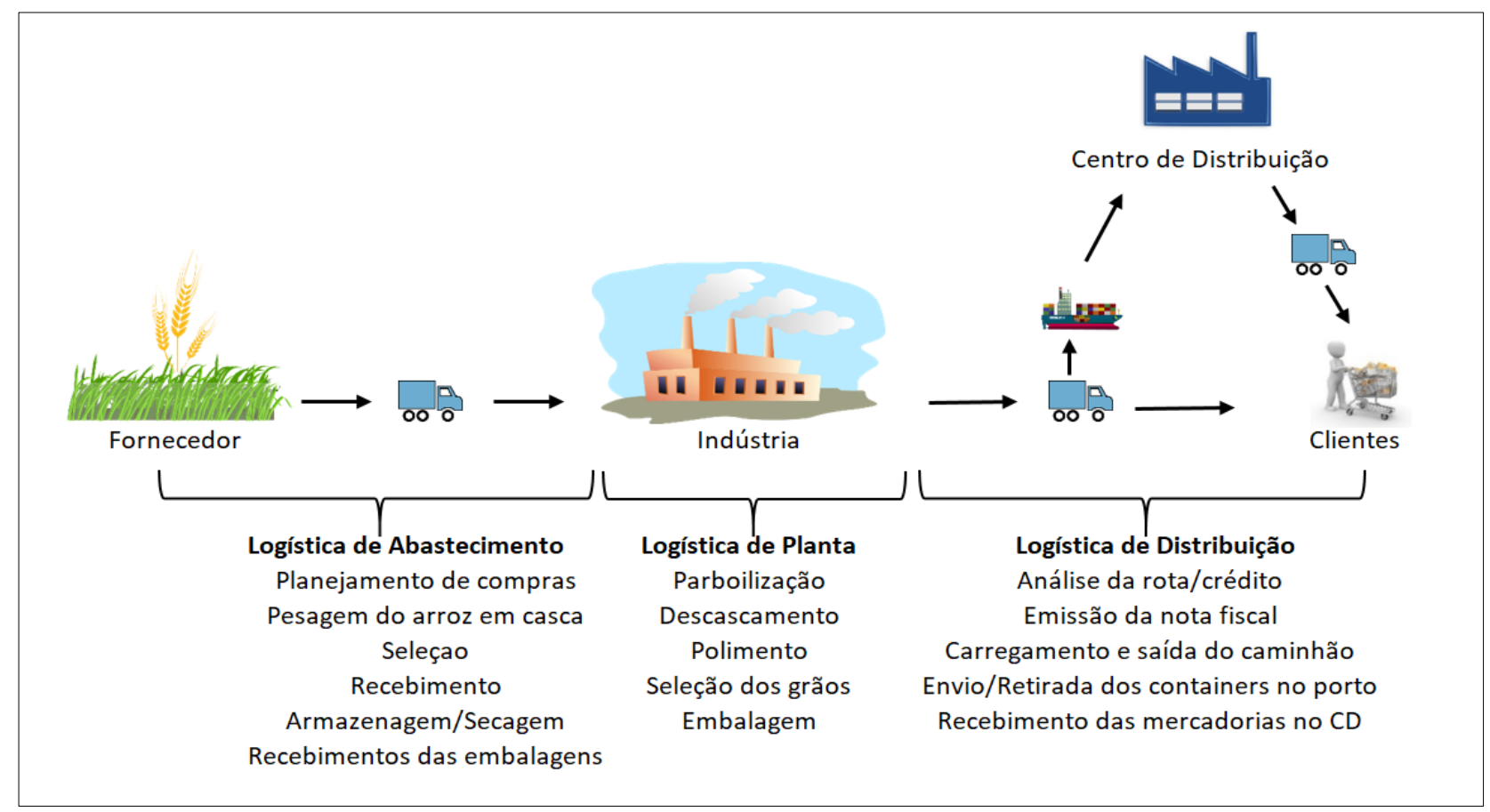

Figura 1. Atividades que integram a cadeia de suprimentos

Fonte: Elaborado pelos autores (2019).

O processo logístico de abastecimento inicia com a aquisição da matéria-prima, arroz em casca. Os principais fornecedores são agricultores localizados na região sul do país, predominantemente em Santa Catarina (92\%) e Rio Grande do Sul (8\%). Destaca-se que a agroindústria também planta arroz em suas fazendas, o que representa $30 \%$ do consumo total de arroz em casca.

A aquisição da matéria-prima ocorre na época da safra de arroz, entre os meses de fevereiro a abril, e fica armazenada em silos por aproximadamente 08 meses, os 03 primeiros para a secagem do grão. Outro insumo representativo são as embalagens, transportadas sob a responsabilidade do fornecedor e recebidas no setor de almoxarifado, que faz a inspeção da espessura e aparência. Após a aprovação, as embalagens são registradas por meio de nota fiscal no estoque e armazenadas.

Os processos da logística de planta compreendem a parboilização, descascamento, polimento, seleção dos grãos e embalagem. $O$ processo de distribuição perfaz os processos de análise da rota e análise de crédito, emissão da 
nota fiscal, carregamento da carga, saída do caminhão, envio/retirada dos containers no porto e recebimento da mercadoria no $C D$.

Os processos logísticos de abastecimento, planta e distribuição para desempenhar suas funções necessitam de suporte dos setores de apoio, como por exemplo, o setor de TI, que por meio dos softwares específicos possibilita o gerenciamento de umidade dos grãos de matéria-prima, dando apoio ao departamento de armazenagem. A unidade fabril é operacionalizada por um sistema de automação, no qual o operador tem controle de todo o processo produtivo, de forma a identificar anomalias e, caso necessário, tomar alguma ação corretiva.

Comparando as atividades logísticas identificadas no presente estudo com os resultados de Franco e Gasparetto (2020), que buscaram avaliar a aplicação de práticas para gestão de custos logísticos em empresas industriais de grande porte na Colômbia, verificou-se certa aderência. Foi observado pelas autoras que mais de $80 \%$ das empresas pesquisadas desenvolvem gestão de estoques, armazenagem e gestão da informação; seguidas por transporte, processamento de pedidos, embalagem e empacotamento e coordenação com outros departamentos da empresa (Franco \& Gasparetto, 2020).

\subsection{Custos logísticos da agroindústria}

A categorização dos custos foi realizada conforme Tabela 1, elaborado com base em Bowersox e Closs (2004) e Faria e Costa (2005). Os custos logísticos da categoria armazenagem e movimentação de materiais contemplam as rubricas salários e encargos, depreciações, manutenção, aluguéis dos centros de distribuição e gastos gerais. Os gastos com salários e encargos referem-se ao funcionário responsável pela pesagem do caminhão no recebimento da matéria-prima, do encarregado e colaboradores do setor de armazém que recebem o arroz em casca e são responsáveis por sua armazenagem nos silos, classificados como custo de Logística de Abastecimento. 
Tem-se nessa categoria, também, os salários e encargos do pessoal responsável pelo centro de distribuição do Pará, alocados como custo de Logística de Distribuição, ressalta-se que a mão de obra do centro de distribuição do Ceará é terceirizada e embutida no preço do aluguel. As depreciações e manutenções estão vinculadas aos silos, máquinas para movimentação de materiais, rampas para carregamento e balança. Os aluguéis referem-se aos dois locais que a empresa utiliza para estocagem e que não são de sua propriedade. Nos gastos gerais estão inclusos água, energia elétrica, Imposto Predial e Territorial Urbano (IPTU) do local aonde estão instalados os silos e a indústria, combustível das empilhadeiras, alvarás e o gás utilizado para secagem do arroz.

A categoria custos de transportes compreende os salários e encargos dos motoristas, funcionários que atuam no carregamento dos caminhões e containers e dos responsáveis pelo setor de logística, os quais estão presentes na Logística de Distribuição; bem como os custos dos fretes sobre vendas, cabotagem/portos, depreciação e manutenção da frota de veículos, combustíveis e seguro dos produtos. Destaca-se que os veículos não possuem seguros, já que os custos não compensam os benefícios.

$\mathrm{Na}$ categoria custos com embalagens estão inseridas as embalagens que acoplam o produto final, plástico filme stretch e paletes, as quais são alocadas na Logística de Distribuição, pois são essenciais para que o produto chegue em bom estado ao consumidor final.

Os custos com manutenção de inventário referem-se aos salários e encargos dos responsáveis pelo setor de compras e almoxarifado, os quais são responsáveis em realizar as compras dos suprimentos necessários e também dos responsáveis pelas negociações de compra de matéria-prima. Destaca-se que o custo de oportunidade de manutenção de estoque não é mensurado pela empresa em estudo.

A categoria custos com tecnologia da informação referem-se ao salário e encargos do funcionário responsável pelo T.I., contempla, ainda, os custos com mensalidade e manutenção de softwares, manutenção e depreciação de hardwares e 
mensalidade de internet. Esses gastos estão presentes na Logística de Abastecimento, Planta e Distribuição. Para este estudo foram consideradas parcelas proporcionais desses custos, de acordo com as informações fornecidas pelo gestor de T.I.

$\mathrm{Na}$ categoria de custos tributários tem-se o IPVA classificado na Logística de Distribuição, pois está associado à frota de veículos. Na organização em estudo não se aplicam os custos decorrentes de lotes, já que não ocorrem paradas de produção necessárias para ajustes das máquinas.

Por fim, no custo decorrente de nível de serviço estão as devoluções, sendo custo de Logística de Planta quando se trata de questões de qualidade do produto e custo de Logística de Distribuição quando estão ligadas às falhas nas entregas; os gastos com o setor de controle de qualidade com salários e encargos; depreciação dos equipamentos; as certificações de qualidade dos produtos; e falhas na produção. Esses considerados como custos de Logística der Planta.

\subsection{Mensuração dos custos logísticos}

Seguindo a metodologia de mensuração dos custos logísticos apresentada por Engblom et al. (2012), utilizou-se os relatórios contábeis e gerenciais da empresa para mensurá-los e se fez uma estimativa em percentuais em relação às vendas. Por meio de entrevistas com os funcionários do setor de contabilidade, realizou-se um levantamento destes gastos em relação às categorias de custos e aos processos logísticos.

A Tabela 1 apresenta os custos logísticos consolidados pertinentes a matriz, filial Rio Grande do Sul, centros de distribuição e fazendas (armazenagem). 
Custos Logísticos: o Caso de uma Indústria Beneficiadora de Arroz

Andréia Cittadin, Kaline Ribeiro Mantovani, Michele Domingos Schneider, Leopoldo Pedro Guimarães

Filho

Tabela 1

Custos logísticos

\begin{tabular}{|c|c|c|c|c|c|c|}
\hline $\begin{array}{l}\text { Custos } \\
\text { Logísticos }\end{array}$ & Descrição & $\begin{array}{l}\text { Logística de } \\
\text { Abastecimento } \\
\text { (R\$) }\end{array}$ & $\begin{array}{l}\text { Logística } \\
\text { de Planta } \\
\text { (R\$) }\end{array}$ & $\begin{array}{l}\text { Logística de } \\
\text { Distribuição } \\
\text { (R\$) }\end{array}$ & Total & $\begin{array}{l}\text { \% sobre } \\
\text { custos } \\
\text { logísticos } \\
\text { totais }\end{array}$ \\
\hline Armazenagem & $\begin{array}{l}\text { Salários e } \\
\text { encargos }\end{array}$ & 1.297 .821 & & 161.940 & 1.459 .761 & $3,18 \%$ \\
\hline \multirow{6}{*}{ Movimentação } & Depreciações & 2.093 .091 & & 52.204 & 2.145 .295 & $4,68 \%$ \\
\hline & Manutenções & 504.006 & & 15.978 & 519.984 & $1,13 \%$ \\
\hline & $\begin{array}{l}\text { Aluguel CD } \\
\text { Ceará }\end{array}$ & & & 330.000 & 330.000 & $0,72 \%$ \\
\hline & $\begin{array}{l}\text { Aluguel CD } \\
\text { Pará }\end{array}$ & & & 108.900 & 108.900 & $0,24 \%$ \\
\hline & Gastos gerais & 1.585 .687 & 24.453 & 10.982 & 1.621 .122 & $3,53 \%$ \\
\hline & $\begin{array}{l}\text { Custo por } \\
\text { processo }\end{array}$ & 5.480 .605 & 24.453 & 680.004 & 6.185 .062 & $13,48 \%$ \\
\hline \multirow{8}{*}{ Transportes } & $\begin{array}{l}\text { Salários e } \\
\text { encargos }\end{array}$ & & & 3.535 .231 & 3.535 .231 & $7,71 \%$ \\
\hline & $\begin{array}{l}\text { Frete sobre } \\
\text { vendas }\end{array}$ & & & 11.534 .737 & 11.534 .737 & $25,15 \%$ \\
\hline & $\begin{array}{l}\text { Cabotagem/po } \\
\text { rtos }\end{array}$ & & & 323.563 & 323.563 & $0,71 \%$ \\
\hline & $\begin{array}{l}\text { Depreciação } \\
\text { frota }\end{array}$ & & & 9.520 .499 & 9.520 .499 & $20,75 \%$ \\
\hline & $\begin{array}{l}\text { Manutenção } \\
\text { frota }\end{array}$ & & & 2.353 .504 & 2.353 .504 & $5,13 \%$ \\
\hline & Combustível & & & 4.159 .954 & 4.159 .954 & $9,07 \%$ \\
\hline & $\begin{array}{l}\text { Seguros } \\
\text { produtos }\end{array}$ & & & 112.831 & 112.831 & $0,25 \%$ \\
\hline & $\begin{array}{l}\text { Custo por } \\
\text { processo }\end{array}$ & 0 & 0 & 31.540 .319 & 31.540 .319 & $68,76 \%$ \\
\hline \multirow{4}{*}{ Embalagens } & Embalagens & & & 2.238 .911 & 2.238 .911 & $4,88 \%$ \\
\hline & $\begin{array}{l}\text { Plástico filme } \\
\text { stretch }\end{array}$ & & & 417.929 & 417.929 & $0,91 \%$ \\
\hline & Pallets & & & 328.373 & 328.373 & $0,72 \%$ \\
\hline & $\begin{array}{l}\text { Custo por } \\
\text { processo }\end{array}$ & 0 & 0 & 2.985 .213 & 2.985 .213 & $6,51 \%$ \\
\hline \multirow{4}{*}{$\begin{array}{l}\text { Manutenção de } \\
\text { Inventário }\end{array}$} & $\begin{array}{l}\text { Salários e } \\
\text { encargos } \\
\text { compras e } \\
\text { almoxarifado }\end{array}$ & 43.060 & & 100.472 & 143.532 & $0,31 \%$ \\
\hline & $\begin{array}{l}\text { Salários e } \\
\text { encargos } \\
\text { comprador }\end{array}$ & 225.390 & & & & \\
\hline & matéria-prima & & & & 225.390 & $0,49 \%$ \\
\hline & $\begin{array}{l}\text { Custo por } \\
\text { processo }\end{array}$ & 268.450 & 0 & 100.472 & 368.922 & $0,80 \%$ \\
\hline \multirow{2}{*}{$\begin{array}{l}\text { Tecnologia de } \\
\text { Informação }\end{array}$} & $\begin{array}{l}\text { Salários e } \\
\text { encargos }\end{array}$ & 13.111 & & 10.727 & 23.838 & $0,05 \%$ \\
\hline & Manutenção e & 17.308 & 23.582 & 10.579 & 51.469 & $0,11 \%$ \\
\hline
\end{tabular}


Custos Logísticos: o Caso de uma Indústria Beneficiadora de Arroz Andréia Cittadin, Kaline Ribeiro Mantovani, Michele Domingos Schneider, Leopoldo Pedro Guimarães

Filho

\begin{tabular}{|c|c|c|c|c|c|c|}
\hline & $\begin{array}{l}\text { Mensalidade } \\
\text { de softwares }\end{array}$ & & & & \multirow[b]{2}{*}{13.656} & \multirow{2}{*}{$\begin{array}{l}0,00 \% \\
0,03 \%\end{array}$} \\
\hline & $\begin{array}{l}\text { Manutenção } \\
\text { de hardwares }\end{array}$ & 4.552 & 4.552 & 4.552 & & \\
\hline & $\begin{array}{l}\text { Depreciação } \\
\text { de hardwares }\end{array}$ & 161.705 & 221.719 & 294.512 & 677.936 & $1,48 \%$ \\
\hline & $\begin{array}{l}\text { Mensalidade } \\
\text { de internet }\end{array}$ & 15.051 & 20.695 & 26.996 & 62.742 & $0,14 \%$ \\
\hline & $\begin{array}{l}\text { Custo por } \\
\text { processo }\end{array}$ & 211.727 & 270.548 & 347.366 & 829.641 & $1,81 \%$ \\
\hline & IPVA & & & 95.934 & 95.934 & $0,21 \%$ \\
\hline Tributários & $\begin{array}{l}\text { Custo por } \\
\text { processo }\end{array}$ & 0 & 0 & 95.934 & 95.934 & $0,21 \%$ \\
\hline \multirow{6}{*}{$\begin{array}{l}\text { Decorrente de } \\
\text { Nível de Serviço }\end{array}$} & Devoluções & & 1.744 .117 & 1.745 .950 & 3.490 .067 & $7,61 \%$ \\
\hline & $\begin{array}{l}\text { Salários e } \\
\text { encargos }\end{array}$ & 24.951 & 224.562 & & 249.513 & $0,54 \%$ \\
\hline & Depreciações & & 79.499 & & 79.499 & $0,17 \%$ \\
\hline & Certificações & & 11.341 & & 11.341 & $0,02 \%$ \\
\hline & $\begin{array}{l}\text { Falhas de } \\
\text { produção }\end{array}$ & & 35.598 & & 35.598 & $0,08 \%$ \\
\hline & $\begin{array}{l}\text { Custo por } \\
\text { processo }\end{array}$ & 24.951 & 2.095 .117 & 1.745 .950 & 3.866 .018 & $8,43 \%$ \\
\hline \multirow{2}{*}{\multicolumn{2}{|c|}{$\begin{array}{l}\text { \% sobre os custos logísticos } \\
\text { totais }\end{array}$}} & 5.985 .733 & 2.390 .118 & 37.495 .258 & 45.871 .109 & $100,00 \%$ \\
\hline & & $13,05 \%$ & $5,21 \%$ & $81,74 \%$ & & \\
\hline
\end{tabular}

Nota. Fonte: Elaborado pelos autores (2019).

Observa-se que os custos logísticos totais representaram 26,25\% sobre o faturamento bruto da empresa, que totalizou $R \$ 174.740 .834,68$ no período pesquisado. Entre as logísticas de abastecimento, planta e distribuição, a que apresenta maior gastos é a logística de distribuição, pois o total de $R \$ 37.495 .258,00$, correspondeu a $81,74 \%$ sobre os custos logísticos totais e $21,46 \%$ do faturamento. Em seguida, se têm os custos com a logística de abastecimento e planta, que foram, respectivamente, de $13,05 \%$ e $5,21 \%$ sobre os custos logísticos totais e 3,43\% e 1,37\% em relação ao faturamento.

Esses resultados vão ao encontro dos achados de Hansen et al. (2014) que apontaram que o custo logístico da indústria e do comércio atacadista norueguês é de, aproximadamente, $13,70 \%$ sobre o faturamento, desses $5,6 \%$ é correspondente aos custos de transporte. Do mesmo modo, porém em menor representatividade, Vargas, 
Custos Logísticos: o Caso de uma Indústria Beneficiadora de Arroz

Andréia Cittadin, Kaline Ribeiro Mantovani, Michele Domingos Schneider, Leopoldo Pedro Guimarães

Filho

Coser e De Souza (2016) verificaram que os custos logísticos correspondem a 5,90\% do faturamento bruto em uma indústria gráfica.

A análise em relação às categorias de custos logísticos evidenciou que o mais significativo é o custo com transporte, correspondente a $68,76 \%$ sobre os custos logísticos totais e $18,05 \%$ do faturamento. Acredita-se que isso se deve pelo fato da empresa possuir frota própria, assim possui elevado valor com depreciação e alto custo com combustível, de $20,75 \%$ e $9,07 \%$, respectivamente, dos custos logísticos totais. Esses resultados convergem com os encontrados na pesquisa de Souza, Weber e Campos (2015), na qual foi constatado que o custo de transporte dos produtos fabricados é o mais significativo e representou $4 \%$ sobre o valor das mercadorias em uma empresa moveleira nacional.

Em seguida, destacou-se o custo com armazenagem e movimentação, equivalente a $13,48 \%$ sobre os custos logísticos totais e $3,54 \%$ em relação ao faturamento, já que inclui um maior número de funcionários, depreciação dos silos, os aluguéis dos centros de distribuição e os gastos gerais da empresa. Esse achado converge com o estudo de Engblom et al. (2012), no qual foi verificado que as indústrias apontaram ter custos de manutenção de estoque em torno de $3,5 \%$ sobre as vendas.

Em terceiro lugar estão os custos Decorrente de Nível de Serviço (8,43\% sobre os custos logísticos totais), de modo que a empresa apresenta valor significativo de devoluções.

\section{CONSIDERAÇÕES FINAIS}

Gerenciar os custos é essencial para o crescimento das organizações, sobretudo, em empresas que precisam escoar sua produção a diversas regiões do país utilizando o modal terrestre. Deste modo, o planejamento e controle logístico contribui para o gerenciamento dos negócios, pois possibilita identificar as atividades que não agregam valor, no intuito de evitar desperdícios e reduzir os custos. Com isso, será 
possível ofertar o produto certo, no lugar certo, com qualidade, melhores preços e níveis de serviços.

Assim, este estudo teve o objetivo de identificar os custos logísticos de uma indústria beneficiadora de arroz do sul catarinense. Em vista disso, apresentou-se a cadeia de suprimentos da agroindústria pesquisada, a qual é composta pelas atividades de recebimento e armazenagem da matéria-prima (arroz em casca), embalagens e demais insumos; processo de beneficiamento do arroz, que ocorre na sede da matriz de Santa Catarina e na filial do Rio Grande do Sul; e distribuição dos produtos finais aos clientes atacadistas e varejistas, envolvendo nesse processo os setores de expedição, vendas e transportes. Portanto, a cadeia de suprimentos da agroindústria engloba os processos logísticos de abastecimento, planta e distribuição.

$\mathrm{Na}$ logística de abastecimento, a matéria-prima adquirida pela indústria é proveniente de agricultores localizados no sul de Santa Catarina e do Rio Grande do Sul, no entanto, a empresa também possui produção própria de arroz. A agroindústria conta com silos de armazenagem para garantir abastecimento das linhas de produção, logística de planta, bem como assegurar a distribuição do produto acabado ao longo do ano. Para o processo de distribuição, a empresa possui frota própria de 32 veículos.

Os custos envolvidos nos processos logísticos foram classificados conforme a literatura proposta por Faria e Costa (2005), relacionando-os com os processos logísticos de abastecimento, plantas e distribuição e mensurados de acordo com uma das propostas apresentadas por Engblom et al. (2012). Dentre os principais identificados neste estudo e que apresentam maior relevância são os custos de transportes, bem como os relacionados à logística de distribuição. A partir da identificação dos custos logísticos foi possível observar que representam $26,25 \%$ sobre o faturamento bruto da empresa.

Esses números embora significativos, ainda estão dentro dos limites apresentados pelo Banco Mundial (Guasch, 2003), no qual os custos logísticos perfazem o percentual de 20,5\% para custos de administração; $19 \%$ como custos de armazenagem; estoques $18,7 \%$; trâmites legais $10,1 \%$; e $31,8 \%$ custos de transportes. 
Custos Logísticos: o Caso de uma Indústria Beneficiadora de Arroz

Andréia Cittadin, Kaline Ribeiro Mantovani, Michele Domingos Schneider, Leopoldo Pedro Guimarães

E, de forma geral, os resultados corroboram com os achados de Hansen et al. (2014) e Souza et al. (2015), que identificaram que os custos logísticos mais significativos estão relacionados ao transporte.

Constatou-se que o gerenciamento adequado dos processos logísticos é essencial para que a organização alcance vantagem competitiva aliada a uma redução desses gastos. Ademais, a pesquisa trouxe contribuições às discussões teóricas da temática à medida que aplicou uma metodologia para mensuração dos custos logísticos relacionando-os com as vendas.

No decorrer da pesquisa foram encontradas algumas limitações, a exemplo tem-se: i) realização do estudo em apenas uma agroindústria beneficiadora de arroz em um único período; ii) dificuldade de visualização nos relatórios contábeis dos custos logísticos, conforme as categorias propostas por Faria e Costa (2005); iii) indisponibilidade de tempo dos gestores de participarem das entrevistas; e iv) os valores expostos são aproximados, tendo em vista a dificuldade de identifica-los nos demonstrativos contábeis e gerenciais.

Como continuidade da pesquisa sugere-se ampliar o estudo no intuito de identificar os custos logísticos por divisão, de modo a possibilitar a análise de desempenho individual da matriz da agroindústria, filial do RS, Centro de distribuição, além de ampliar o período de pesquisa para verificar o comportamento dos gastos logísticos ao longo do tempo.

\section{REFERÊNCIAS}

Agência IBGE Notícias (2017). Levantamento Sistemático da Produção Agrícola. Recuperado de: ftp://ftp.ibge.gov.br/Producao_Agricola/Levantamento_Sistematico_da_Producao_A gricola_\%5Bmensal\%5D/Fasciculo/2017//spa_201701.pdf.

Ballou, R. H. (2001). Gerenciamento da cadeia de suprimentos: planejamento, organização e logística empresarial. Bookman. 
Custos Logísticos: o Caso de uma Indústria Beneficiadora de Arroz

Andréia Cittadin, Kaline Ribeiro Mantovani, Michele Domingos Schneider, Leopoldo Pedro Guimarães

Filho

Ballou, R. H. (2007). Logística Empresarial: transportes, administração de materiais e distribuição física. -19. reimpr. São Paulo: Atlas.

Bowersox, D. J., \& Closs, D. J. (2004). Logística empresarial: o processo de integração da cadeia de suprimento. (1a ed.). São Paulo. Atlas.

Bowersox, D. J., Closs, D. J., \& Cooper, M. B. (2007). Gestão da cadeia de suprimentos e logística. Elsevier.

Cervo, A. L., Bervian, P. A. \& Silva, R. da (2007). Metodologia científica. (6a ed.). São Paulo. Prentice Hal.

Cunha, R. C. C., \& de Melo Cruz, W. L. (2017). Aspectos Geoeconômicos Da Cadeia Produtiva Da Soja No Estado De Santa Catarina: Produção E Circulação. Geo UERJ, (31), 745-769.

Empresa De Pesquisa Agropecuária E Extensão Rural De Santa Catarina - Epagri (2018). Arroz, Histórico da Produção de Arroz Irrigado. Recuperado de: https://www.epagri.sc.gov.br/index.php/tag/cultivares-de-arroz-irrigado/

Engblom, J., Solakivi, T., Töyli, J., \& Ojala, L. (2012). Multiple-method analysis of logistics costs. International Journal of Production Economics, 137(1), 29-35.

Faria, A. C. D., \& Costa, M. D. F. G. D. (2005). Gestão de custos logísticos. São Paulo: Atlas, 147-161.

Faria, A. C., Robles, L. T., \& Bio, S. R. (2004). Custos logísticos: discussão sob uma ótica diferenciada. Congresso Brasileiro de Custos. Porto Seguro, Bahia, Brasil, 11.

Ferreira, J. A. S. (2007). Contabilidade de custos. Pearson Educación.

Franco, M. A. J., \& Gasparetto, V. (2020). Práticas para a gestão de custos logísticos em empresas industriais de grande porte da Colômbia. Estudios Gerenciales, 364373.

Freitas, L. M., \& de Mello Villar, A. (2007). Discussão Sobre as Técnicas de Avaliação dos Custos Logísticos para Fins de Controle Gerencial. Congresso Brasileiro de Custos. João Pessoa, Paraíba, Brasil, 14.

Gasques, J. G., Bastos, E. T., Bacchi, M. R. P., \& Valdes, C. (2010). Produtividade total dos fatores e transformações da agricultura brasileira: análise dos dados dos censos agropecuários. $A$ agricultura brasileira: desempenho, desafios $e$ perspectivas. 
Custos Logísticos: o Caso de uma Indústria Beneficiadora de Arroz

Andréia Cittadin, Kaline Ribeiro Mantovani, Michele Domingos Schneider, Leopoldo Pedro Guimarães

Filho

Guasch, J. L., Straub, S., \& Laffont, J. J. (2003). Renegotiation of concession contracts in Latin America. The World Bank.

Hansen, W., Hovi, I. B., \& Veisten, K. (2014). Logistics costs in Norway: comparing industry survey results against calculations based on a freight transport model. International Journal of Logistics Research and Applications, 17(6), 485-502.

Michel, M. H (2015). Metodologia e pesquisa científica em ciências sociais. São Paulo. Atlas.

Novaes, A. G (2007). Logística e gerenciamento da cadeia de distribuição. Rio de Janeiro. Elsevier.

Rodrigues, P. R. A. (2004). Introdução aos sistemas de transporte no Brasil e à logística internacional. Edições Aduaneiras.

Santos, L. P., Avelar, J. M. B., Shikida, P. F. A., \& de Carvalho, M. A. (2016). Agronegócio brasileiro no comércio internacional. Revista de Ciências Agrárias, 39(1), 54-69.

Silva, T. F. G., \& Leite, M. S. A. (2012). Discussão sobre Custos Logísticos: Estudo de Caso em uma Empresa do Setor Gráfico no Estado da Paraíba. Teoria e Prática em Administração (TPA), 2(1), 114-141.

Sindarroz - Sindicato da Indústria do Arroz no Estado de Santa

Catarina. (2018). Associados. Recuperado de: http://www.sindarrozsc.com.br/default.php?pg=conteudo_2010\&area=Associados.

Soares, T. C., \& Jacometti, M. (2016). Estratégias que agregam valor nos segmentos do agronegócio no Brasil: um estudo descritivo. Revista Eletrônica de Estratégia \& Negócios, 8(3), 92-120.

Souza, R. S., Arbage, A. P., \& Corazza, C. (2006). Gerenciamento da cadeia de suprimentos de engenhos de arroz no Rio Grande Do Sul: um estudo à luz da economia dos custos de transação. Organizações Rurais \& Agroindustriais, 8(1), 49-57.

Souza, M. A., Weber, E. L., \& Campos, R. H. (2015). Práticas de gestão de custos logísticos internos: estudo de caso em empresa moveleira do sul do Brasil. Revista Contemporânea de Contabilidade, 12(25), 27-46. 
Souza, M. A., Zwirtes, A., Rodniski, C. M., \& Borghetti, J. C. (2013). Gestão de custos logísticos: Um estudo das práticas utilizadas por uma cooperativa agroindustrial catarinense. ConTexto, 13(23), 7-22.

Vargas, S. B., Coser, T., \& De Souza, M. A. (2016). Mensuração dos Custos Logísticos: Estudo de Caso em uma Indústria Gráfica. Contabilidade Vista \& Revista, 27(1), 6387.

Data de Submissão: 12/06/2020

Data de Aceite: 09/04/2021 